\title{
Transitional Phenomena on Phase Change Materials
}

\author{
Tadeusz M. Wójcik ${ }^{1, a}$, Robert Pastuszko ${ }^{2}$, Marta Wojda ${ }^{1}$, Wojciech Kalawa ${ }^{1}$ \\ ${ }^{1}$ AGH University of Science and Technology, Faculty of Energy and Fuels, Department of Thermal and Fluid Flow \\ Machines, al. A. Mickiewicza 30, 30 - 059 Krakow, Poland \\ ${ }^{2}$ Kielce University of Technology, Department of Mechanics, Division of Tribology and Operation Materials, al. \\ Tysiąclecia Państwa Polskiego 7, Building B, 25 - 314 Kielce, Poland
}

\begin{abstract}
One of the most significant problem with technology development is transferring of large heat fluxes, which requires constant heat transfer temperature (in the specified temperature range). This problem concern mainly the nuclear energetics, space technologies, military technologies and most of all electronics containing integrated circuits with very large scale of integrations. Intensive heat transfer and thermal energy storage are possible by the use of phase change materials (PCMs). In the paper there are presented preliminary results of research on the use of liquid-gas (L-G PCMs) and solid-solid phase change materials (S-S PCMs). For L-G PCMs the boiling characteristics were determined by increasing and decreasing the heat flux, which for certain sets of structural parameters of the heating surface and the physical properties of the liquid induce a variety of forms of transitional phenomena. Thermal energy storage is much more effective when using PCMs than sensible heat.
\end{abstract}

\section{Introduction}

Energy storage is a constantly evolving issue. Many research studies have focused on this subject. Great interest in this topic come from series of advantages and possibilities associated with energy storage such as:

- reduction of energy consumption,

- reduction o energy cost,

- rationalization of renewable energy sources systems.

Energy storage technics can be classified as follows: mechanical energy storage, chemical energy storage, biological storage, magnetic storage and thermal energy storage. In this paper attention will be focused on thermal energy storage. There are two types of thermal energy storage (TES), a short-term and a long-term storage method. The first type concerns the several-hour energy storage, for example to reduce energy cost by proper electricity management including daily tariffs. Second type relates to thermal energy storage for longer period of time. It can be applied for several-months waste heat storage or seasonal energy storage.

Thermal energy storage can take place with use of chemical methods (chemical or photochemical transitions) or thermal methods (latent and sensible heat storage) [1-2].

Thermal energy storage with the use of chemical transition consists in absorbing and releasing of heat in reversible chemical reaction. In some cases it is necessary to use a catalyst.
In photochemical transition, substance splitting into smaller elements take place. This decomposition proceeds under the influence of monochromatic or visible spectrum. Energy receiving takes place during the decomposition.

Sensible heat storage results in temperature change. Heat flows in the direction from hot to cold. In this case amount of heat stored depends on temperature gradient before and after heating. High value of specific heat at constant pressure is also required.

Latent heat storage is associated with heat absorption or its release during phase transition in the material. One of the energy storage method based on latent heat storage is the use of phase change materials (PCMs). Phase change materials are mainly characterized by certain transition temperature range and the amount of heat released or absorbed during the transition. Scheme of the work of phase change materials is presented on figure 1.

Phase change materials due to their properties, which gives possibility to accumulate heat, can be applied in: -Buildings engineering: Phase change materials as thermal energy storage can be used in dwelling houses or public buildings, to move the energy consumption from periods of highest electricity prices to periods of lower rates. Another application is to use the PCM to maintain thermal comfort conditions in room [3].

-Waste heat recovery - In order to use the waste heat, suitable storage system have to be utilized. It is important

$\overline{\text { a T.M. Wójcik: tmwojcik@agh.edu.pl }}$ 
because period availability is usually different than the period in which waste heat could be used.

-Transport - PCMs can be used for medicine, vaccine, organs or blood transportation.

-Electronics - One of the most important application is stabilization of electronic devices temperature. PCMs allows stable operation of devices, guaranties safety and prevent from failure in case of overheating.

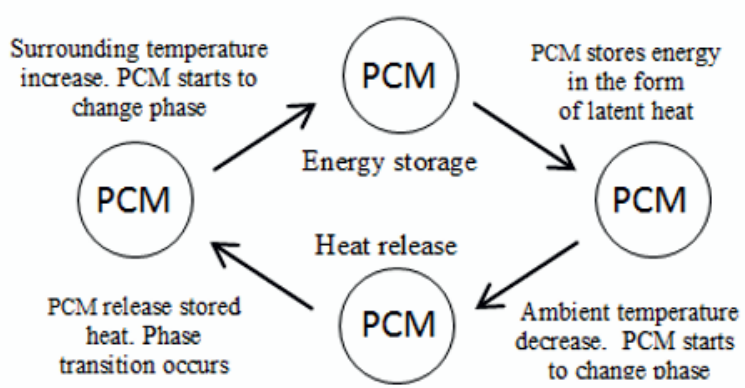

Figure 1 Scheme of the work of phase change materials.

Phase change materials can be grouped by the type of transition: gas-liquid, solid-gas, solid-liquid, solid-solid [4]. The most popular group of PCMs is the one with solid-liquid transition. Recently interest in solid-solid phase change materials (S-S PCMs) has increased strongly. It results from their promising properties.

On the Department of Thermal and Fluid Flow Machines (KCiMP) at Faculty of Energy and Fuels at AGH University of Science and Technology work on two types of phase change materials: liquid-gas and solidsolid is carried out.

\section{Phase change materials}

\subsection{Liquid-gas phase change materials}

Intensification of heat transfer during boiling is important for heat storage and temperature stabilization. At KCiMP research involving heat transfer intensification during the pool boiling and use of different waveforms of boiling curves for thermal stabilization are conducted. Boiling on developed microstructures allows to subtract significant heat fluxes. It is possible because value of heat transfer coefficient for this kind of surface is 10 times higher than for smooth surfaces. The question is how to recover the steam heat generated during the cooling process[5].

In manufacturing processes, where demand on heat energy in the form of steam is variable during the day, it is possible to use steam accumulators. This kind of structural solutions are already used on industrial scale.

Based on experience of researchers from Kielce University of Technology and literature review, the testing rig was designed and built.

Scheme of testing rig for heat transfer examination during the boiling is presented on figure 2 .

This testing rig consists of following modules: - main module(where boiling process take place);1; - heating module(with measurement of supplied electrical power);5;

- temperature measurement module;3;
- electric power supply, control and measurement module, 2;

- liquid supply, steam cooling and condensate recover module, 4;

- visualisation module, 6 .

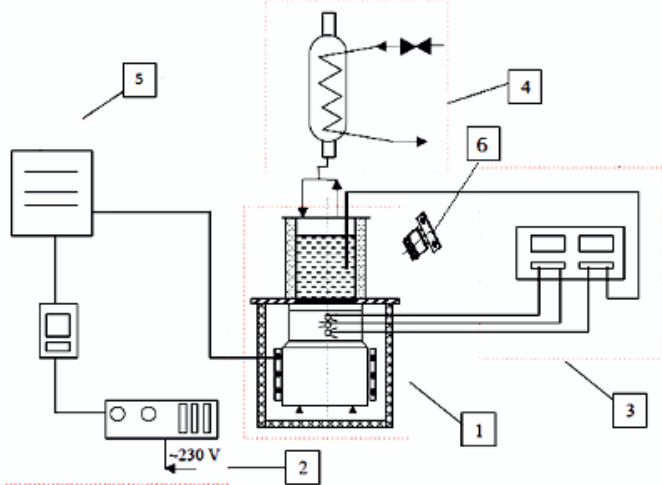

Figure 2 Scheme of testing rig for heat transfer examination during the boiling with cooperating systems.

Basic element of testing rig is the main module. It consist of copper core and $800 \mathrm{~W}$ electric heater wrapped around the core. Holes were drilled in the core (figure 3 ) to place thermocouples in them. There is a copper sample with implemented structure soldered to the core.

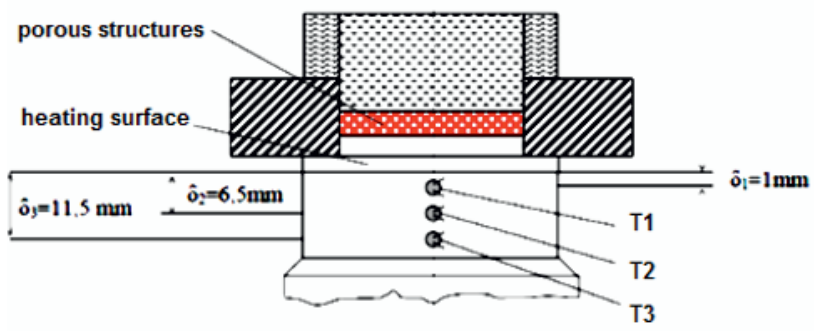

Figure 3 Thermocouples arrangements in the main module.

Pool boiling studies of porous structures were carried out. Before main research were conducted, boiling curve were determined for: smooth copper surfaces, surface coated with a layer of copper oxide, polished surface $(\mathrm{Ra}=0.1)$ and the same surface naturally oxidized. This research were performed for water, ethanol, fluorinert and methanol. Results for mentioned samples were compared with results for samples with developed surfaces. Example of boiling curve for smooth surface is presented in figure 4. Main research of heat transfer intensification were carried out for boiling on the following structures: sintered $\left(\mathrm{Cu}+\mathrm{CuO}_{2}\right)$, metallic fibrous, laser treated with planned structural parameters.

Arrangements of thermocouples in the core are presented in figure 3 [6]. This location of thermocouples allows to determine temperature under the sample by extrapolation of the temperature distribution. 


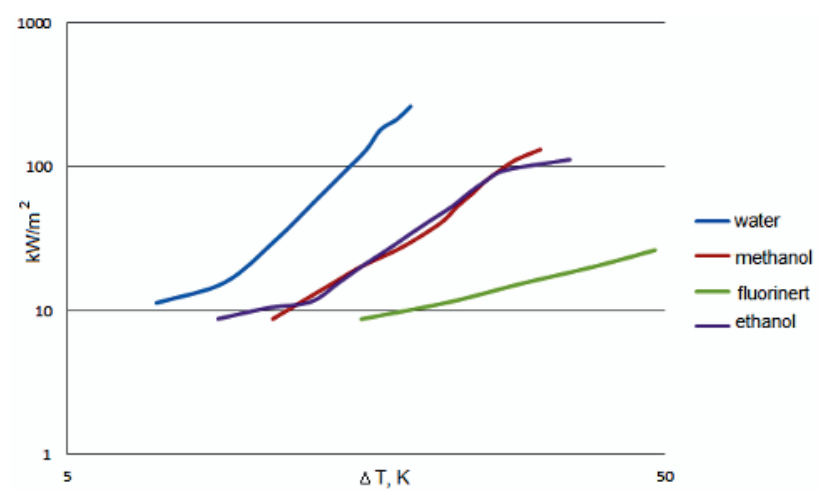

Figure 4 Boiling curves for smooth surfaces (water, methanol, fluorinert, ethanol).

Further research were carried out for laser treated surfaces. Pure aluminium samples were prepared by the method of laser-vibration melting [6-8]. Thanks to this method, it was possible to prepare micro ribs with regular height and width. Research were perform for water in atmospheric pressure. Results are presented in figure 5 . Symbols in the figure correspond to the different heights of joint penetration (details in the figure description). During the research it has been shown that use of this kind of surfaces causes increase of heat transfer coefficient. Additional, it has been observed that during the boiling on pure aluminium surfaces, there is a very intensive process of surface ageing which reduce the heat transfer.

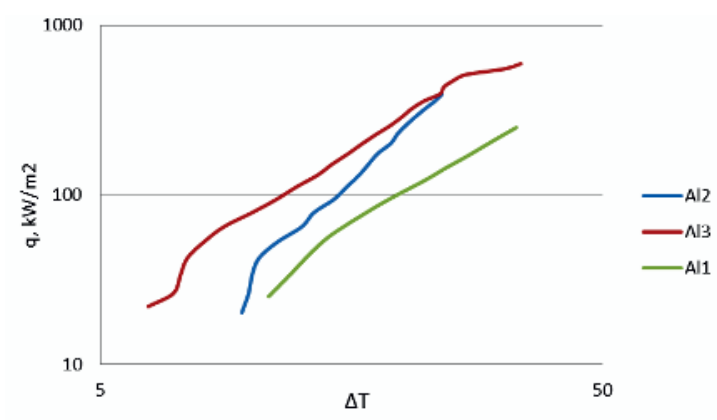

Figure 5 Boiling curves obtained for the testing of heat transfer during boiling for the aluminium surfaces. All - smooth aluminium sample, A12 - laser treated aluminium sample with small joint penetration height, A13 - laser treated aluminium sample with maximal.

Wójcik [9-10] used the results of his own research of boiling curves for porous structures for heating surfaces temperature stabilization.

Stability and repeatability of the curves for boiling with type-II hysteresis help present a new approach to boiling heat transfer control on heating surfaces coated with porous layers. Those two features of type-II hysteresis decided about its name "controlled hysteresis". The described phenomenon can find applications in the control of heating surface temperature. The heat source, to which the control refers, is cooled with the use of boiling process on the surface coated with CPS. The technique of control is presented in figure 6 . At the unwanted change in the heat flux emitted by the source (for instance from $\mathrm{q}_{1}$ to $\mathrm{q}_{2}$ ), it is possible to find such point $\mathrm{B}$ on the curve $\mathrm{b}$ that after the next heat flux decrease to the set value, the constant temperature difference of the heating surface and liquid saturation $\Delta \mathrm{T}_{\mathrm{n}}$ can be obtained. This requires that an additional heat source emitting heat flux $\mathrm{q}_{\text {ad }}$ is used for the time necessary to reach point $\mathrm{B}$. The procedure of heat transfer surface temperature control has been patented [9].

The heating surface temperature equalization for the case presented in figure 7 is shown in [10]. The patent has used the dependence of the heat flux on the superheat, and porous coating porosity and thickness. Figure 7 presents the parameters of the coating (porosity, thickness) which allow maintaining constant temperature of the surface for the variable flux.

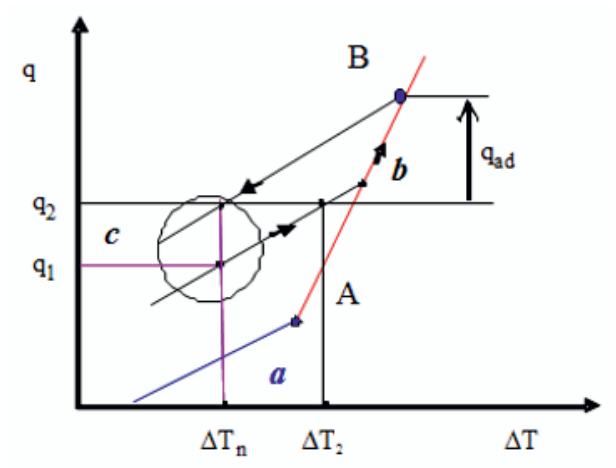

Figure 6 Heat transfer control method.

Low Heat Flux
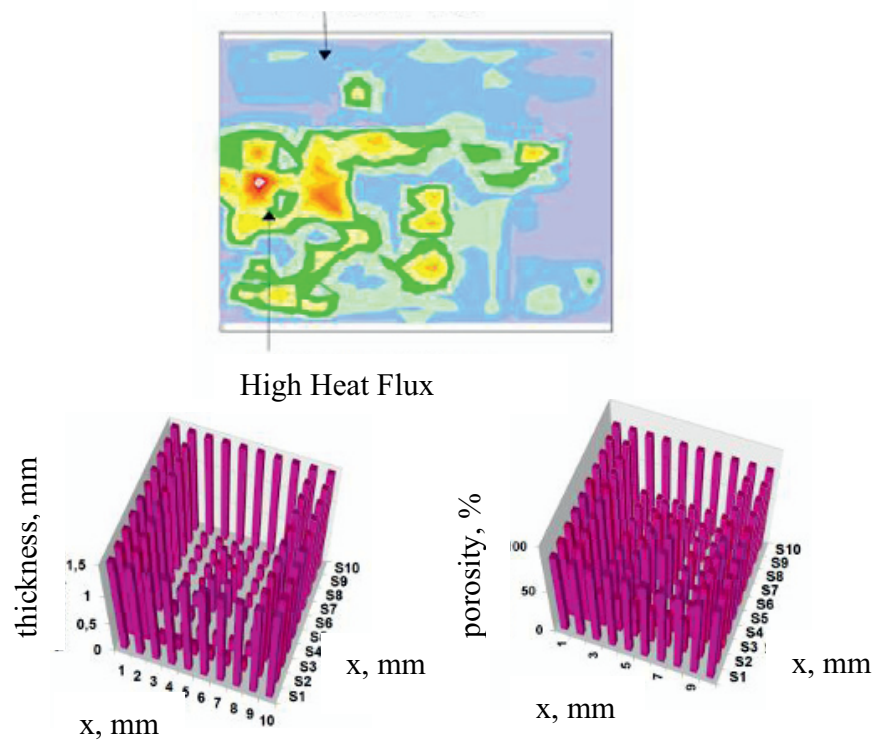

Figure 7 Application of capillary-porous structure to equalization of computer processor temperature [9].

\subsection{Solid-solid phase change materials}

The work of polymeric solid-solid phase change materials is based on transition between different molecular structures:

-between amorphous and crystalline structure -between two different crystalline structure -between two different amorphous structure 
Important is, that it is not typical transition, like for example in metals. This kind of transition is not completely known and described yet.

During the solid-solid transition there is no liquid or gas form in any of transition stage, so using this group of materials brings number of benefits. These include primarily:

- very small volume change during the transition,

- no problem of leakage or liquid and gas generation,

- minimization or no corrosion problem.

Unfortunately, S-S PCM are characterized by a relatively low latent heat (compared to S-L PCM). It also happens that they have unstable thermal properties.

Due to large potential of S-S PCM, synthesis of S-S PCM based on polyethylene glycol (PEG) and ethyl cellulose was performed. Synthesised material will be tested in the matter of possibility of thermal stabilization of electronic devices application. Number of syntheses were carried out. Polyethylene glycol with different molecular weights has been used: PEG 2000, PEG 4000, PEG 8000 and PEG 12000. Comparison of temperature range and absorbed latent heat during the transition of synthesized materials is presented as DSC curves in figure 10. DSC curves show that value of heat transition depends on kind of polyethylene glycol used for synthesis. For material with PEG 2000 heat transition is insignificant, almost imperceptible. The latent heat increase for materials containing PEG of higher molecular weight. Transition temperature is also changing. It increase with increase of PEG molecular weight.

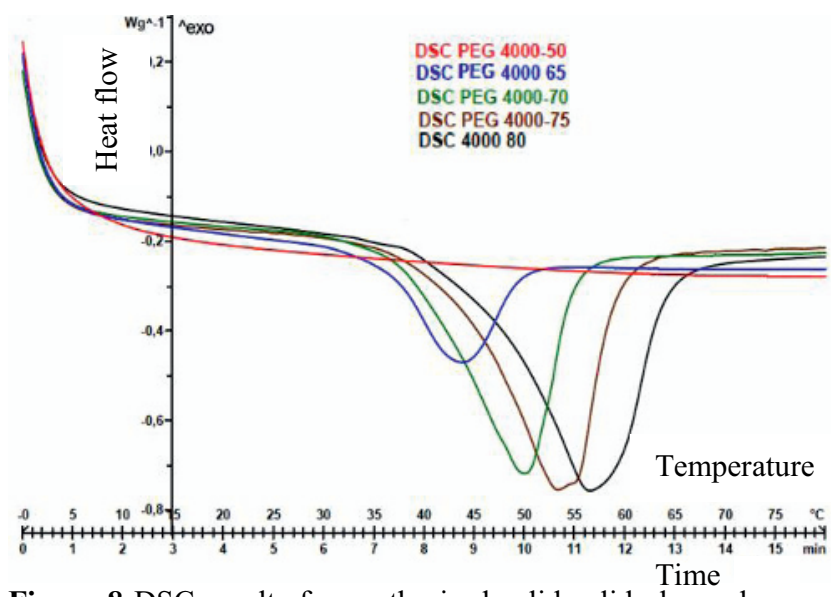

Figure 8 DSC results for synthesised solid-solid phase change materials, measurement $5 \mathrm{deg} / \mathrm{min}$, air atmosphere.

\section{Conclusions}

Importance of phase change materials increase for modern technology. PCMs provide:

- possibilities of large heat fluxes transferring,

- maintain constant temperature of the heat sources

- possibility of much more effective thermal energy storage than for accumulation.

At KCiMP work on the use of two kind of PCMs: liquid-gas and solid-solid is ongoing.

Many years of research on liquid-gas PCMs has resulted in significant ( $\sim 10$ times) increase of heat transfer factor for boiling (compared to smooth surface). Use of specific boiling curves (depend on L-G PCM type and the structural parameters of the heating surface) allows specify methods for thermal stability of hating surfaces.

Preliminary work with solid-solid phase change materials allows to choose material for further work on thermal stabilisation of electronic devices. Material characterized by suitable transition temperature $\left(52-55^{\circ} \mathrm{C}\right)$ and quite high latent heat $(73 \mathrm{~J} / \mathrm{g})$ has been synthesized: material based on polyethylene glycol and ethyl cellulose, which consist $75 \%$ of polyethylene glycol.

\section{References}

1. A.Sharma, V.V. Tyagi, C.R. Chen, D. Buddhi, Review on thermal energy storage with phase change materials and applications, Renewable and Sustainable Energy Reviews 13, 318-345 (2009)

2. R. Domański, Biuletyn Informacyjny Instytutu Techniki Cieplnej Politechniki Warszawskiej, 62, 29-58 (1983)

3. Ł.J. Orman, Structure and Environment, 1, vol. 2, $41-45$ (2010)

4. B. Zalba, J. M. Marin, L.F.Cabeza, H. Mehling, Applied Thermal Engineering 23, 251-283 (2003)

5. T.M. Wójcik., M.E. Poniewski, A. Dziadoń, W. Depczyński., R. Kaniowski, Termodynamika w nauce i gospodarce, Oficyna Wydawnicza Politechniki Wrocławskiej 1, 554-561 (2008)

6. B. Grabas, Sposób zwiększania powierzchni czynnej elementów metalowych, zwłaszcza powierzchni wymiany ciepła elementów metalowych, Patent 210889 (2011)

7. B. Grabas, Sposób zwiększania powierzchni wymiany ciepla elementów metalowych, zwłaszcza powierzchni wymiany ciepła elementów metalowych, Patent 210889 (2010)

8. B. Grabas, Laserowo-wibracyjna metoda zwiększania powierzchni wymiany ciepła elementów metalowych, Zeszyty Naukowe Politechniki Świętokrzyskiej, Budowa i Eksploatacja, 17/2012, 50-58 (2011)

9. B. A. Afanasjew, M.E. Poniewski, T.M.Wójcik, Method for heat transfer control, Patent P-176683, Polish Patent Office, Warsaw (1999)

10. T.M. Wójcik, M.E. Poniewski, Method for temperature reduction and equalization on the heat transfer surface under varied thermal loads, Patent P-379266, Polish Patent Office, Warsaw (2008) 